\title{
Effects of reading span and textual coherence on rapid-sequential reading
}

\author{
HSUAN.CHIH CHEN \\ University of Kansas, Lawrence, Kansas
}

\begin{abstract}
Subjects' comprehension and memory of conventional presentations (pages) and rapid, serial visual presentations (RSVPs) of text were investigated with a statement-recognition test. Texts were presented with sentences in an intact or a scrambled order at rates of 300 and 600 words per minute (WPM). Subjects' memory for text meaning and surface structure was better in 300 than in 600-WPM conditions, and subjects retained more textual meaning from coherent than incoherent texts regardless of display rates. These findings are inconsistent with the idea that rapid reading disrupts the intersentence integration processes of comprehension, but are consistent with the hypothesis of consolidation limitation. Furthermore, subjects were separated into two groups based on their performance on the reading span test of Daneman and Carpenter (1980). Low-span subjects retained significantly less text meaning than high-span subjects with pages, but they did almost as well with RSVPs. This interaction suggests that the RSVP technique could be useful for improving the reading abilities of less efficient readers.
\end{abstract}

Reading has concerned psychologists and educators for a long time (e.g., Huey, 1908/1968), not only because it reflects one of the most complex mental activities, but also because the ability to read well is critical for academic and job success. However, researchers have noted that reading mastery is not an easy goal to achieve, and there may be room for improvement even for skilled adult readers (see, e.g., Daneman \& Carpenter, 1980; Gilbert, 1959; Juola, Ward, \& McNamara, 1982; Potter, Kroll, \& Harris, 1980; Raygor, 1974). Naturally, it is important to know what factors are responsible for the rate and effectiveness of reading.

Inefficient motor components of reading (e.g., irregular regressions and mislocations of line beginnings) have been considered as one of the limiting factors for reading rate. Gilbert (1959), for example, reported that "readers can process simple prose material mentally at a faster rate and more accurately than they actually do when reading with saccadic movements"' (p. 19). Indeed, researchers have found that elimination of the requirement for eye movements facilitates performance in visual search (Lawrence, 1971), in sentence recall (Gilbert, 1959; Potter et al., 1980), and in reading for comprehension (Raygor, 1974). The general research technique that has

The author was supported by a dissertation fellowship from the University of Kansas while the present research was conducted and during the initial preparation of this article.

The author is indebted to Patricia Carpenter for providing the materials and the instructions of the reading span test; to Ed Martin, Sue Kemper, and Ed Wike for comments on the study; to Alice Healy, Lyle Bourne, Erik Kvan, and Michael Bond for comments on earlier versions of this article; and most especially to Jim Juola for advice in all stages of this research. The author is also grateful to Roberta Klatzky, Michael Masson, Mary Potter, and an anonymous reviewer for valuable comments and suggestions that substantially improved the article.

The author is now at the Department of Psychology, The Chinese University of Hong Kong, Shatin, N.T., Hong Kong. been used in these studies is the rapid, serial visual presentation (RSVP) method. In RSVP conditions, the need for eye movements in reading is eliminated by having a subject fixate a single location on a screen and letting mechanical or electronic devices present text segments successively to that location. Since important input variables, such as the size and duration of text segments presented, can be experimentally controlled without interfering with normal comprehension processes, this method has been used extensively to study reading and its related processes (for a recent review, see Potter, 1984).

Although the effects of inefficient eye movements on reading are eliminated in RSVP reading, there seem to be other factors that limit the rate and effectiveness of reading. Potter et al. (1980) reported that a rapidly presented text was poorly remembered, even though it seemed to be understood at the time of reading: subjects rarely missed the topic sentence at any of the display rates used (from 240 to 720 words per minute [WPM]). Therefore, Potter et al. suggested that the performance decrements at high rates of reading could be due to the failure to consolidate what has already been understood. Alternatively, readers might fail to establish detailed connections among the ideas in the text during initial comprehension. However, the comprehension and memory processes in reading rapidly presented texts have not been extensively investigated. The present study was designed to fill this gap.

To examine the subjects' integration processes, textual coherence was manipulated by presenting the sentences of a narrative text in normal or scrambled order. The idea is that this procedure of scrambling destroys the intraparagraph coherence which serves to integrate the sentences into a general, coherent representation (e.g., Kintsch, Mandel, \& Kozminsky, 1977; Thorndyke, 1977). Thus, differences in performance for subjects reading paragraphs 
with sentences in an intact versus a scrambled order would indicate whether normal integration processes have occurred. In addition, to assess the subjects' long-term retention in reading RSVP texts, subjects' reading performance was tested both immediately after the display of each paragraph and at the end of all the presentations.

In the present experiment, two display rates (i.e., 300 and 600 WPM) were chosen to investigate RSVP reading at both normal and higher rates. In the 300-WPM conditions, one would expect to find better performance for coherent paragraphs than for incoherent paragraphs, as found by previous researchers (e.g., Kintsch et al., 1977; Thorndyke, 1977). If the higher rate of RSVP reading disrupts the normal integration process, then no textual coherence advantage should be found in the 600-WPM condition. If, on the other hand, the important determinant at higher rates of RSVP reading is the lack of time to stabilize what has already been understood in the postcomprehension stage of consolidation memory, then the coherence advantage should still be found in the 600-WPM condition. Moreover, a conventional page condition was included to serve as the control condition.

Finally, it is commonly observed that there are large individual differences among readers. Previously, Just, Carpenter, and Woolley (1982) pointed out a possibility that the effectiveness of RSVP reading might depend on individual differences. To investigate this possibility, the reading span test developed by Daneman and Carpenter $(1980,1983)$ was adopted in the present experiment. This particular test was chosen because the scores on this test presumably reflect a reader's processing efficiency (Daneman \& Carpenter, 1980, 1983; Masson \& Miller, 1983). Previous researchers have suggested that different readers execute similar reading processes for comprehension, but that the readers differ in efficiency (see, e.g., Lesgold \& Perfetti, 1978). Such efficiency differences imply that efficient readers may have lighter demands on processing resources (e.g., working memory capacity; see Daneman \& Carpenter, 1983) than do less efficient readers; thus, efficient readers have more capacity for storing the products of reading processes or for performing some extra tasks during reading. In the reading span test, a subject is asked to read aloud a series of unrelated sentences continuously and then recall the final word of each sentence. The ability to manage this additional task (i.e., storing the final word of each sentence while reading) becomes the measurement of the reading span test. This measurement has been shown to correlate well with reading proficiency (see Daneman \& Carpenter, 1980, 1983; Masson \& Miller, 1983).

Because the RSVP technique can eliminate the need for resource-demanding eye-movement control activities in reading (see, e.g., Chen, Healy, \& Bourne, 1985, for relevant reviews), and because less efficient readers presumably devote more capacity to activities and processes of reading than do efficient readers, it seems reasonable to predict that this technique would be beneficial to at least less efficient readers, if not to all readers. If this is the case, the results of the present study should show that RSVP would lead to better performance than would page reading for less efficient readers.

\section{METHOD}

\section{Subjects}

Thirty-two native-English-speaking undergraduates participated for research credit in an introductory psychology class at the University of Kansas. All subjects reported normal or corrected-to-normal vision.

On Day 1 of the experiment, each subject's processing efficiency was measured by the reading span test (details of which are described in the Materials and Procedure sections). The reading span scores for the 32 subjects varied from 2 to 6 (mean $=2.9$ ). To determine whether subjects' individual differences in processing efficiencies interacted with other variables, reading span was used as a grouping variable in the analyses, as reported in the Results section. A high-span group was formed by subjects who had a reading span of 3.0 or higher. Two subjects who had a reading span of 3.0, but whose correct recalls in the span test were less than that for the high-span subjects, were grouped with the 14 subjects who had a reading span of 2.5 or below, to form a low-span group.

\section{Apparatus}

The stimuli were presented on a Teleray cathode ray tube (CRT) terminal interfaced to a DEC PDP-11/03 minicomputer with a realtime clock. During the experiment, the front of the CRT was placed approximately $.7 \mathrm{~m}$ from the subject's position so that a four-letter lower-case word subtended a horizontal visual angle of about $1^{\circ}$. To reduce glare on the CRT screen, the experiment was conducted in a semidarkened room.

\section{Materials}

One hundred unrelated sentences (13-20 words in length) were used for the reading span test. Each sentence ended in a different word. Eighty-eight sentences were taken from those constructed by Daneman and Carpenter (1980) and arranged to form five sets each of $2,3,4$, and 5 sentences, and three sets of 6 sentences. The remaining 12 sentences were constructed by the author to form two sets of 6 sentences.

For the reading comprehension part of the experiment, 16 paragraphs (mean $=181$ words) from the McCall-Crabbs Reading Test (McCall \& Schroeder, 1979) Books D, E, and F were used as the coherent paragraphs. The incoherent paragraphs were formed by scrambling the sentences of the coherent paragraphs into a random order, with the constraint that no two consecutive sentences fell into the original sequence.

For each of the 16 paragraphs, three types of recognition statements, with four statements from each type, were constructed. These included true exact (TE), true paraphrase (TP), and false paraphrase (FP) statements. The TE statements were exact excerpts from the text. The TP statements were constructed by re-forming the surface structure of exact excerpts but were consistent in meaning with the text. The FP statements were formed by paraphrasing an idea unit so as to create a statement that contradicted the original idea. (Examples of different types of paragraphs and recognition statements are shown in Table 1). The statements from each type were randomly chosen to form two equal sets of tests, which were counterbalanced across subjects and conditions. To ensure that subjects could not judge the statements as having or not having come from a given text without first having read the text, 10 pilot subjects were asked to rate each statement as a TE, a TP, or a FP statement without reading the paragraphs. The average percentages of correct judgments to the TE, TP, and FP items were $39 \%, 41 \%$, and $36 \%$, respectively. No reliable differences were found in a statistical analysis of these data $(F<1)$. 
Table 1

Examples of a Coherent Paragraph, an Incoherent Paragraph, and Three Recognition Statements

\section{Coherent Paragraph:}

The discovery was entirely accidental. The two boys were searching for cattle that had strayed from the herd. The part of the plain over which they rode was separated from the inaccessible, and apparently useless mesa by a turbulent stream. Jack had once seen a horse swim the river and disappear up the narrow box canyon of the mesa. Although the place had always been avoided by herders with cattle, the boys decided to cross and reconnoiter in search for the strays. They made their objective a high point that seemed to be the edge of the mesa. After an hour's climb they reached their lookout and beheld, in the cliffs above them a city-a sleeping city of stone! There, nestled in a great cavern, beautifully proportioned and symmetrically made, was a village of little tinted, flat-roofed houses. "Mirage" was their first thought. Then they realized that they were looking at the ruins of an ancient, extinct civilization. Preserved, in calm repose, were the homes of some of the forebears of our American Indians.

\section{Incoherent Paragraph:}

The part of the plain over which they rode was separated from the inaccessible, and apparently useless, mesa by a turbulent stream. Then they realized that they were looking at the ruins of an ancient, extinct civilization. After an hour's climb they reached their lookout and beheld, in the cliffs above them, a city-a sleeping city of stone! "Mirage" was their first thought. The two boys were searching for cattle that had strayed from the herd. Although the place had always been avoided by herders with cattle, the boys decided to cross and reconnoiter in search of the strays. There, nestled in a great cavern, beautifully proportioned and symmetrically made, was a village of little tinted, flat-roofed houses. Preserved, in calm repose, were the homes of some of the forebears of our American Indians. They made their objective a high point that seemed to be the edge of the mesa. The discovery was entirely accidental. Jack had once seen a horse swim the river and disappear up the narrow box canyon of the mesa.

\section{True Exact Statement:}

The place had always been avoided by herders.

True Paraphrase Statement:

After an hour's climb they reached the edge of the mesa.

False Paraphrase Statement:

The two boys were searching for a city of stone

\section{Procedure}

The reading span test was given to each subject on Day 1 of the experiment. Unrelated sentences were presented on the CRT screen one at a time. The subject was asked to read the sentence aloud at his/her own pace. As soon as the sentence was read, the experimenter replaced the sentence by another, and the subject read the new sentence. This procedure was repeated until a string of stars signaled that a trial had ended and that the subject was to recall the last word of each of the sentences in the order in which they had occurred. Subjects were given two practice items at the twosentence level before the test began. Subjects were presented with increasingly longer sets of sentences until they failed all five sets at a particular level. The level at which a subject was correct on three out of five sets was taken as a measure of the subject's reading span. However, if the subject was correct on only two out of the five, he or she was given a score of .5 .

On Day 2 of the experiment, the subjects were asked to read coherent and incoherent paragraphs shown in both page and RSVP formats. In the RSVP format, paragraphs were sectioned into segments, approximately 12 characters in length, without truncating a word. This segment size was chosen because an earlier study had shown it to be the best size over other size conditions for presenting RSVP text (Cocklin, Ward, Chen, \& Juola, 1984, Experiment 2). (However, in a later study, Cocklin et al., 1984, Experiment 3 , found that the optimal RSVP segments should be constrained to be consistent with text structural variables.) At the end of each sentence, one segment composed solely of spaces was inserted to simulate useful pauses between sentences in conventional reading, following Potter et al. (1980). All text segments were justified toward the left margin and displayed sequentially one at a time to a common central locus on the screen. In the page format, each paragraph was displayed in its entirety for a fixed length of time and then erased. Within each display mode, the paragraphs were presented such that the reading rates required to complete the texts were 300 or 600 WPM.

In both page and RSVP formats, the subjects were instructed to press the return key on the terminal keyboard to initiate a trial and to read each text to the best of their abilities. Each trial began with an instruction to "Read Normally" (for the 300-WPM condition) or to "Read Rapidly" (for the 600-WPM condition) shown on the screen for 2 sec. The instruction was followed by a mask of overlapped Xs and Os for $1 \mathrm{sec}$. For the page conditions, the mask completely filled the screen, whereas for the RSVP conditions, the mask filled only the central location of the screen at which the segments were displayed. Following the mask, the text was displayed and then a second mask appeared. Immediately after the second mask, six recognition statements were displayed individually in a conventional format. The subjects were instructed to judge each statement on surface structures and not on general meaning alone. They made their responses by pressing the keys numbered 1-4 on the keyboard. Subjects were instructed to press 1 (or 2) if they were confident (or guessing) that the statement did not occur in the text or 4 (or 3 ) if they were confident (or guessing) that the statement occurred in the text.

The page and RSVP conditions were blocked, and the order of these conditions was counterbalanced across subjects. The order of paragraph presentations within each display mode was randomized for each subject. Across subjects, each paragraph occurred equally often in each experimental condition. Each experimental session began with the instructions and with a set of four practice trials.

At the end of the test for the final paragraph, an unexpected test was given. There were 16 additional statement sets, each including six recognition trials (none of which had occurred in the immediate tests). The order of these test sets was matched to the order of the paragraphs. At the beginning of each set, a message "Questions for Paragraph No." (No. was replaced by the appropriate number in the experiment) was displayed

\section{RESULTS}

\section{Rating Scores}

Each subject's mean rating response under each condition was computed. In order to make ratings for the three types of statements comparable, the ratings for the TP and FP statements were subtracted from 5, following Rafnel and Klatzky (1978). After this transformation, all rating scores represent confidence for the correct response, with 4 as the maximum confidence. The data were initially analyzed using an analysis of variance (ANOVA) with one between-subjects factor (reading span) and five withinsubjects factors (display mode, paragraph type, time of test, display rate, and statement type). The analysis found neither a significant main effect for time of test nor any reliable interaction involving this factor. The data were thus collapsed across this factor and are presented in Table 2 . The standard error of the values in Table 2 , as determined by the analysis, is .102 . The significance level in this and other analyses was set at the $p<.05$ level.

The analysis indicated that the performance of high-span subjects (mean $=2.60$ ) was superior to that of low-span subjects (mean $=2.49)[F(1,30)=5.09]$; that the over- 
Table 2

Mean Rating Scores as a Function of Display Mode, Paragraph Type, Display Rate (WPM), Statement Type, and Reading Span

\begin{tabular}{|c|c|c|c|c|c|c|c|c|}
\hline \multirow[b]{4}{*}{ Statement Type } & \multicolumn{8}{|c|}{ Display Mode } \\
\hline & \multicolumn{4}{|c|}{ RSVP } & \multicolumn{4}{|c|}{ Page } \\
\hline & \multicolumn{2}{|c|}{ Coherent } & \multicolumn{2}{|c|}{ Incoherent } & \multicolumn{2}{|c|}{ Coherent } & \multicolumn{2}{|c|}{ Incoherent } \\
\hline & 300 & 600 & 300 & 600 & 300 & 600 & 300 & 600 \\
\hline \multicolumn{9}{|c|}{ High-Span Subjects } \\
\hline True Exact & 3.18 & 2.82 & 2.89 & 2.84 & 3.16 & 2.81 & 2.95 & 2.82 \\
\hline False Paraphrase & 2.64 & 2.57 & 2.77 & 2.51 & 3.02 & 2.63 & 2.79 & 2.50 \\
\hline True Paraphrase & 2.06 & 2.15 & 2.31 & 2.23 & 2.17 & 2.27 & 2.19 & 2.19 \\
\hline \multicolumn{9}{|c|}{ Low-Span Subjects } \\
\hline True Exact & 3.15 & 2.93 & 3.09 & 2.88 & 3.07 & 2.81 & 2.98 & 2.77 \\
\hline False Paraphrase & 2.48 & 2.45 & 2.53 & 2.30 & 2.42 & 2.31 & 2.37 & 2.41 \\
\hline True Paraphrase & 1.95 & 2.14 & 2.05 & 2.10 & 2.16 & 2.01 & 2.15 & 2.30 \\
\hline
\end{tabular}

all performance was higher in the 300-WPM condition (mean $=2.61)$ than in the 600-WPM condition (mean = 2.49) $[F(1,30)=16.94]$; and that among different types of statements, the highest performance was found for the TE statements and the lowest for the TP statements [the mean scores for TE, FP, and TP statements were 2.95, 2.54 , and 2.15 , respectively; $F(2,60)=51.07]$.

Furthermore, the statement-type factor was involved in two significant interactions, statement $\times$ display rate $[F(2,60)=10.95]$ and statement $\times$ paragraph type $[F(2,60)=4.60]$, and one marginally significant interaction, statement $\times$ reading span $\times$ display mode $[F(2,60)$ $=2.69, p<.08]$. In order to explore the pattern of these interactions, the rating scores for the three types of statements were converted to two sets of signal detection measures of $d^{\prime}$ reflecting subjects' memory for meaning and surface structure, following Rafnel and Klatzky (1978). The idea was that "old" responses (i.e., 3 or 4 ) to TE items reflected memory for meaning and surface structure, "old" responses to TP items reflected meaning only, and "old" responses to FP items reflected neither. Based on this reasoning, subjects' "old" responses to TP items were used as false alarms and the correct "old" responses to TE items were used as hits for computing the $d^{\prime}$ values for surface structure. To compute the $d^{\prime}$ values for meaning, the "old" responses to FP items were used as false alarms and the "old" responses to TP items were used as hits. The procedure used by Pezdek and Chen (1982) was followed for calculating $d^{\prime}$ values. Two separate ANOVAs (with span, display mode, paragraph type, and display rate as factors) were performed on the obtained $d^{\prime}$ values.

\section{$d^{\prime}$ Values for Meaning}

The mean $d^{\prime}$ values for meaning are presented in Table 3 (the standard error is .353). The analysis indicated that the subjects retained more text meaning in the 300than in the 600-WPM condition (means = 1.05 and .69) $[F(1,30)=9.39]$; that subjects retained more meaning information from coherent paragraphs than from incoherent paragraphs (means $=1.03$ and .71$)[F(1,30)=4.47]$; and that high-span subjects obtained higher $d^{\prime}$ values for meaning than did low-span subjects (means $=1.01$ and .73) $[F(1,30)=4.21]$. Note that although both the display-rate and paragraph-type factors were significant, they did not interact with each other $(F<1)$. This result indicated that subjects were equally sensitive to the manipulation of textual coherence in both 300 - and 600-WPM conditions.

The most important result was a significant interaction between reading span and display mode $[F(1,30)=5.51]$. This interaction arose because in the page condition, highspan subjects obtained higher $d^{\prime}$ values for meaning than did low-span subjects (means $=1.13$ and .59) $[t(30)=$ 2.88 ], whereas in the RSVP condition, no significant difference was found between these two groups (means $=.90$ and .86$)[t(30)=.17]$. Alternatively, RSVP reading led to better performance than page for low-span subjects $[t(15)=2.64]$, whereas no significant difference between RSVP and page was found for high-span subjects $[t(15)=1.20]$. No other significant results were found in this analysis.

In order to further investigate the reading span $x$ display mode interaction, an analysis of two sets of $d^{\prime}$ values for meaning (they were computed based on recognition statements whose content appeared in the first vs. the second half of a passage) was performed, following Masson (1983) and Potter et al. (1980). In an ANOVA with display mode and paragraph half as within-subjects factors

Table 3

Mean $d^{\prime}$ Values for Meaning as a Function of Display Mode, Paragraph Type, Display Rate (WPM), and Reading Span

\begin{tabular}{|c|c|c|c|c|}
\hline \multirow[b]{3}{*}{ Display Rate } & \multicolumn{4}{|c|}{ Display Mode } \\
\hline & \multicolumn{2}{|c|}{ RSVP } & \multicolumn{2}{|c|}{ Page } \\
\hline & Coherent & Incoherent & Coherent & Incoherent \\
\hline \multicolumn{5}{|c|}{ High-Span Subjects } \\
\hline 300 & 1.32 & 1.00 & 1.58 & 1.17 \\
\hline 600 & 0.83 & 0.42 & 1.00 & 0.75 \\
\hline \multicolumn{5}{|c|}{ Low-Span Subjects } \\
\hline 300 & 1.23 & 0.84 & 0.60 & 0.66 \\
\hline 600 & 0.91 & 0.46 & 0.73 & 0.39 \\
\hline
\end{tabular}


(and reading span as a between-subjects factor), the mode $X$ span interaction $[F(1,30)=4.48]$ and the mode $X$ half interaction $[F(1,30)=5.17]$ were significant. The span $X$ mode $X$ half interaction, however, was not significant $(F<1)$; nor were other results in this analysis. These results indicated that: (1) the pattern of the mode $\times$ span interaction was similar in both the first and second halves of the text and (2) in the first half of the text, page reading appeared to have higher $d^{\prime}$ values for meaning than RSVP (means $=1.03$ and .77), but the difference between the two conditions was not reliable $[t(31)=1.17, p=$ .25]; in the second half, RSVP led to better performance than page reading (means $=1.21$ and .81$)[t(31)=2.10]$. (Note that direct comparisons between two paragraph halves are unwarranted because the two halves were not matched for difficulty.)

\section{$d^{\prime}$ Values for Surface Structure}

Table 4 presents the mean $d^{\prime}$ values for surface structure (the standard error is .305). In general, the $d^{\prime}$ values were very low in each condition. In fact, the analysis revealed only one significant effect, for display rate $[F(1,30)$ $=4.27]$, indicating that subjects retained more surface information in the 300-WPM condition than in the 600WPM condition (means $=.34$ and .04 ).

\section{DISCUSSION}

The present research demonstrated that memory for meaning was better in 300 - than in 600-WPM conditions and that subjects retained more text meaning from coherent paragraphs than from incoherent paragraphs in both normal and fast display conditions. The finding that readers are sensitive to textual coherence even at the higher rate of reading is inconsistent with the hypothesis that the limitation for rapid reading is the intersentence integration processes of comprehension (the integration processes are presumably responsible for organizing ideas into a general coherent representation). It appears that fast display rates disrupt a postcomprehension, memoryconsolidation stage of processing (cf. Potter, 1984, and Potter et al., 1980, for a similar suggestion). Presumably, as reading rate increases, heavier demands are placed on the processing resources of the readers than at normal reading speeds. Consequently, fewer resources are available to stabilize the information in memory.

Table 4

Mean $d^{\prime}$ Values for Surface Structure as a Function of Display Mode, Paragraph Type, Display Rate (WPM), and Reading Span

\begin{tabular}{|c|c|c|c|c|}
\hline \multirow[b]{3}{*}{ Display Rate } & \multicolumn{4}{|c|}{ Display Mode } \\
\hline & \multicolumn{2}{|c|}{ RSVP } & \multicolumn{2}{|c|}{ Page } \\
\hline & Coherent & Incoherent & Coherent & Incoherent \\
\hline \multicolumn{5}{|c|}{ High-Span Subjects } \\
\hline 300 & 0.33 & 0.40 & 0.54 & 0.12 \\
\hline 600 & -.13 & 0.14 & 0.13 & -.05 \\
\hline \multicolumn{5}{|c|}{ Low-Span Subjects } \\
\hline 300 & 0.23 & 0.35 & 0.51 & 0.25 \\
\hline 600 & 0.07 & 0.02 & -.19 & 0.31 \\
\hline
\end{tabular}

Furthermore, it appears that subjects retained very little surface information from the text, in contrast to their memory for the text meaning. In fact, subjects' memory for surface structure was only affected by display rate. Apparently, small changes in the original text were often missed if they altered only its surface structure, as in the case of TP statements, but were often detected if they altered its meaning, as in the FP statements. These results are not particularly surprising since it has been reported that people usually remember only the meaning of a text and not its exact surface form (see, e.g., Sachs, 1967). Note that although the subjects' memory for text meaning and surface structure was influenced by display rate and paragraph type, these factors did not interact with display mode. These results imply that general comprehension processes are similar for both normal and RSVP reading and are probably independent of a variety of input methods (for similar suggestions, see Potter, 1984; Potter et al., 1980; and Ward \& Juola, 1982).

The present study further demonstrated that subjects retained more text meaning from RSVP reading than from page reading in the second half of the text, whereas an opposite pattern was found in the first half (see Potter et al., 1980, Experiments 1 and 2, for a similar finding with recall). These results are in line with the suggestion of Potter et al. (1980) that subjects spent more reading time on the first half of the text in page reading (but see Masson, 1983, Experiments 1 and 4). It appears although general comprehension processes seem to be similar for page and RSVP reading, readers may apply different processing strategies in RSVP and page reading.

The final concern of the present study was the factor of individual differences in RSVP reading. The results showed that, as expected, high-span subjects were superior to low-span subjects in the statement-recognition test. Further analyses indicated that high-span subjects derived more text meaning than did low-span subjects. The most striking result to be noted was the significant interaction between reading span and display mode for meaning retention measures. In the page condition, lowspan subjects retained less paragraph meaning than highspan subjects, whereas in the RSVP condition, low-span subjects did almost as well as high-span subjects. Apparently, high-span subjects were more skilled readers and processed the conventional page format efficiently, whereas low-span subjects were less skilled readers in the conventional page condition. While reading, a low-span reader presumably placed more demands on processing resources, such as working memory capacity, than did a high-span reader (Daneman \& Carpenter, 1983). Thus, a low-span reader had available less capacity for storing the products of reading processes. In RSVP reading, however, text segments were rapidly and automatically available. This simpler reading task could then allow more processing capacity to be devoted to maintain relevant information and subsequently improve comprehension analysis. This is probably why the results showed that the less efficient low-span readers gained an advantage from 
RSVP reading. Alternatively, it might be argued that the RSVP over page advantage observed for the low-span subjects was due to the fact that the RSVP procedure can guarantee exposure of all the text to the reader, but the time-limited page procedure cannot. If this is the case, one would expect to find that the RSVP superiority effect found for low-span subjects varied by paragraph half (so that, for example, the RSVP superiority effect appeared in the second half but not in the first half of the text). However, no evidence of this sort was found.

Note that a similar RSVP over page advantage was not found for high-span subjects. Perhaps high-span readers are better able to maximize assimilation of information from the page reading method than are low-span readers. High-span readers' well-practiced techniques might be limited by other features of RSVP reading, such as the lack of control over what is seen and for how long, and thus they are unable to use processing strategies that distribute attention over the text in ways that assist normal reading. Their performance for RSVP reading presumably was not as good as that for page reading. In fact, Patberg and Yonas (1978) have discussed the possibility that skilled reading may be disrupted to a greater degree than less skilled reading by tasks requiring modifications of well-practiced techniques. However, a more efficient system would also be expected to be more flexible and independent of input methods. It is, then, no surprise that even though high-span subjects' meaning retention scores in RSVP were not as good as those in page reading, the difference was not significant.

In summary, when using RSVP to study reading processes, most previous researchers have failed to recognize the importance of individual differences (see, Potter, 1984, for a recent review). The present study illustrates the existence of individual differences for the usefulness of the RSVP procedure: the technique has shown advantages over the conventional page presentation method for a group of less efficient but capable adult readers. This result is striking but is consistent with previous findings that the execution of eye-movement control activities and the increasing complexity of visual display demand attention and processing resources and interfere with comprehension processing (see, e.g., Chen et al., 1985; Gilbert, 1959; Lawrence, 1971; Willows, 1974, 1978). In addition, Breitmeyer (1983) recently reviewed physiological and clinical data in reading and visual exploration and reported that visuosensory and visuomotor deficiencies are both important sources of reading difficulty. In RSVP reading, the display is relatively simple (i.e., one segment at a time), important input parameters such as segment size and display rate can be manipulated, and the need for eye-movement control activities can be removed. Consequently, this procedure should lessen the burden that conventional reading places on processing resources of less efficient readers and allow them to devote their full capacities to the task of com- prehension. The results of the present study, therefore, have potential implications for educational practices, to the extent that they suggest that RSVP could be used with less skilled readers as an effective technique for teaching reading skills and eliminating reading deficiencies.

\section{REFERENCES}

BREITMEYer, B. G. (1983). Sensory masking, persistence, and enhancement in visual exploration and reading. In $\mathrm{K}$. Rayner (Ed.), Eye movements in reading (pp. 3-30). New York: Academic Press.

Chen, H.-C., Healy, A. F., \& Bourne, L. E., JR. (1985). Effects of presentation complexity on rapid-sequential reading. Perception \& Psychophysics, 38, 461-470.

Cocklin, T. G., Ward, N. J., Chen, H.-C., \& Juola, J. F. (1984). Factors influencing readability of rapidly-presented text segments. Memory \& Cognition, 12, 431-442.

Daneman, M., \& Carpenter, P. A. (1980). Individual differences in working memory and reading. Journal of Verbal Learning \& Verbal Behavior, 19, 450-466

Daneman, M., \& Carpenter, P. A. (1983). Individual differences in integrating information between and within sentences. Journal of Experimental Psychology: Learning, Memory, \& Cognition, 9, 561-584.

GILBERT, L. C. (1959). Saccadic movements as a factor in visual perception in reading. Journal of Educational Psychology, 50, 15-19.

HUEY, E. B. (1968). The psychology and pedagogy of reading. Cambridge, MA: MIT Press. (Originally published, 1908.)

JUOLA, J. F., WARD, N., \& MCNAMARA, T. (1982). Visual search and reading of rapid, serial presentations of letter strings, words, and text. Journal of Experimental Psychology: General, 111, 208-227.

Just, M. A., Carpenter, P. A., \& Woolley, J. D. (1982). Paradigms and processes in reading comprehension. Journal of Experimental Psychology: General, 111, 228-238.

Kintsch, W., Mandel, T., Kozminsky, E. (1977). Summarizing stories. Memory \& Cognition, 5, 547-552.

LAWRENCE, D. (1971). Two studies of visual search for word targets with controlled rates of presentation. Perception \& Psychophysics, 10, 85-89.

Lesgold, A. M., \& Perfetti, C. A. (1978). Interactive processes in reading comprehension. Discourse Processes, 1, 323-336.

Masson, M. E. J. (1983). Conceptual processing of text during skimming and rapid sequential reading. Memory \& Cognition, 11, 262-274.

Masson, M. E. J., Miller, J. A. (1983). Working memory and individual differences in comprehension and memory of text. Journal of Educational Psychology, 75, 314-318.

MCCALL, W. A., \& SCHROEDER, L. C. (1979). McCall-Crabbs standard test lessons in reading. New York: Teachers' College Press.

Patberg, J. P., Yonas, A. (1978). The effects of the reader's skill and the difficulty of the text on the perceptual span in reading. Journal of Experimental Psychology: Human Perception \& Performance, 4, 545-552.

Pezdek, K., \& Chen, H.-C. (1982). Developmental differences in the role of detail in picture recognition memory. Journal of Experimental Child Psychology, 33, 207-215.

POTTER, M. C. (1984). Rapid serial visual presentation (RSVP): A method for studying language processing. In D. E. Kieras \& M. A. Just (Eds.), New methods in reading comprehension research (pp. 91118). Hillsdale, NJ: Erlbaum.

Potter, M. C., Kroll, J. F., \& Harris, C. (1980). Comprehension and memory in rapid-sequential reading. In R. Nickerson (Ed.), $A t$ tention and Performance VIII (pp. 395-418). Hillsdale, NJ: Erlbaum.

RAFNEL, K. J., \& KLATZKY, R. L. (1978). Meaningful-interpretation effects on codes of nonsense pictures. Joumal of Experimental Psychology: Human Learning \& Memory, 4, 631-646.

RAYGOR, R. (1974). An investigation of the relationship between eye movements and comprehension in fluent readers. Unpublished doctoral dissertation, University of Minnesota. 
SACHS, J. D. S. (1967). Recognition memory for syntactic and semantic aspects of connected discourse. Perception \& Psychophysics, 2, 437-442.

ThORNDYKe, P. W. (1977). Cognitive structures in comprehension and memory of narrative discourse. Cognitive Psychology, 9, 77-110.

WARD, N. J., JuoLA, J. F. (1982). Reading with and without eye movements: Reply to Just, Carpenter, and Woolley. Journal of Experimental Psychology: General, 111, 239-241.
Willows, D. M. (1974). Reading between the lines: Selective attention in good and poor readers. Child Development, 45, 408-415.

WILLows, D. M. (1978). Individual differences in distraction by pictures in a reading situation. Journal of Educational Psychology, 70, 837-847.

(Manuscript received August 20, 1985; revision accepted for publication November 13,1985 .)

\section{ANNOUNCEMENTS}

\section{6th Annual Meeting \\ Society for Computers in Psychology}

The 16th Annual Meeting of the Society for Computers in Psychology will be held at the Hyatt Regency Hotel, New Orleans, Louisiana, November 12, 1986. The meeting features papers on applications of computers to all areas of psychology-experimental, clinical, and educationalwith the emphasis on on-line, laboratory applications. Contact: Cyndi McDaniel, Psychology Department, Northern Kentucky University, Highland Heights, Kentucky 41076; (606) 572-5310.

\section{Call for Papers \\ Society for Computers in Psychology}

Papers and symposia are sought for the 16th Annual Meeting of the Society for Computers in Psychology, November 12, 1986, New Orleans, Louisiana. Deadline for papers: July 1, 1986. For more information, contact Cyndi McDaniel, Psychology Department, Northern Kentucky University, Highland Heights, Kentucky 41076; (606) 572-5310.

\section{Student Paper Competition Society for Computers in Psychology}

The Society for Computers in Psychology will continue to sponsor an award for the outstanding student paper submitted for presentation at the annual meeting. Although the primary emphasis of the meeting is the use of computers in on-line, experimental applications, student papers in any area of the application of computers to psychology are welcome. Papers may be theoretical, experimental, or applied in approach. Eligibility is open to (1) work done by a student currently enrolled in undergraduate or graduate courses or (2) work done as part of a course, thesis, or other student research by a person who has graduated in 1986. All papers submitted for the meeting (including multiply authored ones) in which the major contribution has been made by a student are eligible for the prize, and will be considered for presentation at the meeting and subsequent publication. The winning paper will be presented at the 1986 meeting, and the author will receive a complimentary 1-year membership in the meeting, a complimentary 1-year subscription to $\mathrm{Be}$ havior Research Methods, Instruments, \& Computers, and a $\$ 50$ cash prize. Deadline for papers: July $1,1986$.

Eligible papers should be submitted in quadruplicate. A cover sheet should include the author's name, mailing address, telephone number, and academic affiliation, a 50-word abstract, and a note stating that the paper is to be considered for the student award. These materials should be sent to: Cyndi McDaniel, Psychology Department, Northern Kentucky University, Highland Heights, Kentucky 41076; (606) 572-5310.

The winner of the 1985 competition was Brian Watts of New York University, whose paper is published in these Proceedings. 